escalating the dose of the biologic therapy. Limited data exist on how theses therapy modifications are used in patients with PsA receiving biologic treatment in real-world settings.

Objectives: To describe therapy modifications (adding non-biologic medications or dose escalation of the current biologic therapy) in patients with PsA receiving biologic therapy in the United States.

Methods: This study used US administrative claims data from the Optum Research Database. Adults with PsA who newly initiated (no evidence of use in the 12 months prior) a biologic between January 1, 2013 and January 31, 2015, and were continuously enrolled in a commercial or Medicare Advantage health plan 12 months before (baseline period) and 15 months following the index date, defined as the date of first pharmacy fill or medical infusion, were included. To reduce confounding by patients with an early switch/discontinuation, therapy modifications were identified only in those patients who persisted with their index biologic for $>90$ days. Therapy modifications identified included initiation of addon medications (disease-modifying antirheumatic drugs [DMARDs], nonsteroidal anti-inflammatory drugs [NSAIDs], opioids, corticosteroids, antidepressants, anxiolytics, sleeping aids and topical analgesics) after the first 90 days of persistence, and dose escalation of the index biologic. Dose escalation was defined as a patient receiving a dose $>10 \%$ above the reference dose from the product label for $\geq 90$ days.

Results: Of the 1,010 patients included who persisted on their index biologic for $>90$ days, $80.5 \%$ initiated a subcutaneous tumor necrosis factor inhibitor (TNFi-SC; adalimumab, certolizumab pegol, etanercept or golimumab) as their index biologic, $12.0 \%$ initiated an intravenous TNFi (TNFi-IV; infliximab) and $7.5 \%$ initiated ustekinumab. During the 12-month baseline period, patients had a mean (standard deviation) number of claims of 2.9 (4.3) for conventional synthetic DMARDs (csDMARDs), 2.6 (5.0) for opioids, 2.2 (3.1) for NSAIDs and 2.0 (2.9) for corticosteroids. Overall, $45.5 \%$ of patients received $\geq 1$ additional medication during the period from 90 days after the index date to the end of persistence with the index biologic or immediate 12-month post-index period. The most commonly added medications were corticosteroids (22.0\%), opioids (17.1\%), NSAIDs (12.9\%) and csDMARDs (5.3\%) (Table 1). Overall, $9.6 \%$ of patients had a dose escalation of the index biologic (33.9\% for TNFi-IV, $6.4 \%$ for TNFi-SC and $5.3 \%$ for ustekinumab) in the immediate 12 -month post-index period.

Table 1. Add-on medications initiated from 90 days after the index date to the end of persistence or 12 months among patients with PsA

\begin{tabular}{|c|c|c|c|c|}
\hline Add-on Medication, $\mathrm{n}(\%)$ & $\begin{array}{c}\text { Total } \\
(\mathbf{N}=\mathbf{1 0 1 0})\end{array}$ & $\begin{array}{c}\text { TNFi-SC } \\
(\mathbf{n}=\mathbf{8 1 3})\end{array}$ & $\begin{array}{c}\text { Infliximab } \\
(\mathbf{n}=\mathbf{1 2 1})\end{array}$ & $\begin{array}{c}\text { Ustekinumab } \\
(\mathbf{n}=\mathbf{7 6})\end{array}$ \\
\hline Any medication & $460(45.4)$ & $353(43.4)$ & $62(51.2)$ & $45(59.2)$ \\
\hline Corticosteroid & $222(22.0)$ & $168(20.7)$ & $37(30.6)$ & $17(22.4)$ \\
\hline Opioid & $173(17.1)$ & $126(15.5)$ & $20(16.5)$ & $27(35.5)$ \\
\hline NSAID & $130(12.9)$ & $105(12.9)$ & $14(11.6)$ & $11(14.5)$ \\
\hline csDMARD & $54(5.3)$ & $43(5.3)$ & $8(6.6)$ & $3(3.9)$ \\
\hline Antidepressant & $49(4.9)$ & $34(4.2)$ & $8(6.6)$ & $7(9.2)$ \\
\hline Anxiolytic & $48(4.8)$ & $34(4.2)$ & $10(8.3)$ & $4(5.3)$ \\
\hline Topical analgesic & $31(3.1)$ & $24(3.0)$ & $4(3.3)$ & $3(4.0)$ \\
\hline Sleeping aid & $22(2.2)$ & $17(2.1)$ & $4(3.3)$ & $1(1.3)$ \\
\hline tsDMARD & $11(1.1)$ & $9(1.1)$ & $0(0.0)$ & $2(2.6)$ \\
\hline
\end{tabular}

cSDMARD, conventional synthetic disease-modifying antirheumatic drug; NSAID, nonsteroidal anti-inflammatory drug; PSA, psoriatic arthritis; SC, subcutaneous; TNFi, tumor necrosis factor inhibitor; tsDMARD, targeted synthetic DMARD

* TNFi-SC includes adalimumab, certolizumab pegol, etanercept and golimumab.

Conclusions: In this descriptive, administrative claims-based study, nearly onehalf $(\approx 45 \%)$ of patients with PsA receiving biologic therapy initiated an add-on medication, most of which were pain medications. Further research is needed to better understand the reasons for therapy modifications during biologic treatment and the impact of insufficient control of pain in patients with PsA in the United States.

Acknowledgements: This study was sponsored by Novartis Pharmaceuticals Corporation, East Hanover, NJ.

Disclosure of Interest: J. Walsh Consultant for: Novartis, O. Adejoro Employee of: Optum, B. Chastek Employee of: Optum, G. Chun Employee of: Novartis, J. Palmer Employee of: Novartis

DOI: 10.1136/annrheumdis-2017-eular.3014

\section{SAT0457 MIXED ANXIETY-DEPRESSIVE DISORDER (MADD) IN PATIENTS WITH PSORIATIC ARTHRITIS TREATED WITH BIOLOGICAL THERAPY}

C. García-Porrúa ${ }^{1}$, J.A. Mosquera-Martínez ${ }^{2}$, F.J. Maceiras-Pan ${ }^{3}$, L. Fernandez-Dominguez ${ }^{4}$, L. Guerra-Vazquez ${ }^{5}$, J. Pinto-Tasende $^{6}$ ${ }^{1}$ Rheumatology, Hospital Universitario de Lugo, Lugo: ${ }^{2}$ Rheumatology, Complejo Hospitalario Universitario de Pontevedra, Pontevedra; ${ }^{3}$ Rheumatology, Complejo Hospitalario Universitario de Vigo, Vigo; ${ }^{4}$ Rheumatology, Complejo Hospitalario Universitario de Ourense, Ourense, ${ }^{5}$ Rheumatology, Complejo Hospitalario
Universitario de Ferrol, Ferrol; 6 INIBIC-Rheumatology, Complejo Hospitalario Universitario A Coruña, A Coruña, Spain

Background: Psoriasis makes stress in patients and stress could play a role on the onset and exacerbation of psoriasis. Psoriasis and psoriatic arthritis (PsA) are associated with a variety of psychological problems, mainly anxiety and depression, although most of patients suffer from both anxiety and depressive symptoms of limited and equal intensity accompanied by at least some autonomic features and excluding severe anxiety and depressive symptoms (mixed anxietydepressive disorder or MADD).

Objectives: The aim of this study was to describe the prevalence of MADD in clinical practice among PsA patients from our registry on treatment with biological therapy (bDMARDs) and to analyze their possible relation with characteristics of the disease or treatments in these patients.

Methods: We included all PsA patients (met CASPAR criteria) following treatment with bDMARDs and included in our regional registry (reference population 2.055.000). Was recorded the history of attending a mental health consultation since PsA diagnoses and before starting biologics therapy and if they were diagnosed as a mixed of anxiety and depression disorder (F41.2, ICD-10) and treated by non severe anxiety and depressive symptoms. We used for this analysis sex, age, disease duration, current bDMARDs with or without current co-medication with csDMARDs (methotrexate or leflunomide or sulfasalazine) and HLA-B27 status. Continuous variables were reported as mean \pm standard deviation. Categorical variables were reported as percentages and frequencies. All analyses were performed using SPSS software. Differences were considered statistically significant if $p<0.05$ (two-tailed).

Results: We have registered 604 PsA patients who have been treated with bDMARDs. Three-hundred and twenty nine (54.5\%) patients were men, mean age was $53.3 \pm 12.6$ years and disease duration of PSA was $12.4 \pm 8.7$ years. MADD was diagnosed in 99 patients $(16.4 \%)$, and was more frequent in women than in men $(21.1 \%$ vs $12.5 \%, p=0.004)$, with no differences in age of diagnosis and disease duration of PsA, nail disease, dactylitis, uveitis or HLA-B27. MADD was more prevalent in patients with enthesitis $(31.9 \%$ vs $12.0 \%, p<0.0001)$ and PsA with axial involvement was associated with MADD ( $p=0.003)$. Etanercept $(42 \%)$ and adalimumab (36\%) were bDMARDs more used $-56.2 \%$ with associated csDMARDs - and $67.9 \%$ of patients remained in the first biologic with a mean follow-up of 4.9 years. Infliximab was most used bDMARDs in patients with previous MADD $(p=0.001)$.

Conclusions: Mixed anxiety-depressive disorder was more prevalent in women with PsA in our registry. It was associated more frequently with the axial disease, enthesitis and most use of infliximab like bDMARDs established in these patients. References:

[1] McDonough E, Ayearst R, Eder L, Chandran V, Rosen CF, Thavaneswaran A, Gladman DD. Depression and anxiety in psoriatic disease: prevalence and associated factors. J Rheumatol. 2014;41(5):887-96.

Acknowledgements: The authors are grateful for the support of the members of the Galician Society of Rheumatology (SOGARE).

Disclosure of Interest: None declared

DOI: 10.1136/annrheumdis-2017-eular.4015

\section{SAT0458 IDENTIFICATION OF GENETIC VARIATION SPECIFICALLY ASSOCIATED WITH PSORIATIC ARTHRITIS USING GENOME-WIDE ASSOCIATION STUDIES}

J.D. Cañete $^{1}$, A. Aterido $^{2}$, J.A. Pinto ${ }^{3}$, J. Gratacós $^{4}$, R. Queiró ${ }^{5}$, C. Montilla ${ }^{6}$, J.C. Torre-Alonso ${ }^{7}$, J.J. Pérez-Venegas ${ }^{8}$, A. Fernández-Nebro ${ }^{9}$,

S. Muñoz-Fernández ${ }^{10}$, C. González ${ }^{11}$, D. Roig ${ }^{12}$, P. Zarco ${ }^{13}$, A. Erra $^{14}$,

J. Rodríguez ${ }^{15}, \mathrm{~S}$. Castañeda ${ }^{16}$, E. Rubio ${ }^{17}, \mathrm{G}$. Salvador ${ }^{18}$, C. Díaz-Torné ${ }^{19}$

R. Blanco ${ }^{20}$, A. Willisch-Domínguez ${ }^{21}$, J.A. Mosquera ${ }^{22}$, P. Vela $^{23}$, J. Tornero $^{24}$, S. Sánchez-Fernández ${ }^{25}, \mathrm{H}$. Corominas ${ }^{12}, \mathrm{~J}_{\text {. Ramírez }}{ }^{1}$, A. Pluma $^{2}$,

M. López-Corbeto ${ }^{2}$, M. López-Lasanta ${ }^{2}$, R. Tortosa $^{2}$, N. Palau ${ }^{2}$, S. Marsal ${ }^{2}$,

A. Julià ${ }^{2} .{ }^{1} \mathrm{H}$. Clínic Barcelona and IDIBAPS; ${ }^{2}$ Vall Hebron Research Institute;

${ }^{3} \mathrm{CH}$. Juan Canalejo, Barcelona; ${ }^{4} \mathrm{H}$. Parc Taulí, Sabadell; ${ }^{5} \mathrm{H}$. Univ. Central

Astúrias, Oviedo: ${ }^{6} \mathrm{H}$. Virgen de la Vega, Salamanca: ${ }^{7} \mathrm{H}$. Monte Naranco,

Oviedo; ${ }^{8} \mathrm{H}$. SAS Jerez Frontera, Cádiz; ${ }^{9} \mathrm{H}$. Reg. Univ. Málaga, Málaga; ${ }^{10} \mathrm{H}$.

Univ. Infanta Sofía; ${ }^{11} \mathrm{H}$. Univ. Gregorio Marañón, Madrid; ${ }^{12} \mathrm{H}$. Moisès Broggi,

Barcelona: ${ }^{13} \mathrm{H}$. Univ. Fundación Alcorcón, Madrid; ${ }^{14} \mathrm{H}$. Sant Rafael; ${ }^{15} \mathrm{H}$. Univ.

Bellvitge, Barcelona; ${ }^{16} \mathrm{H}$. Univ. la Princesa, IIS-Princesa, Madrid; ${ }^{17}$ Centro Salud

Virgen Reyes, Sevilla; ${ }^{18} \mathrm{H}$. Mútua Terrassa, Terrassa; ${ }^{19} \mathrm{H}$. Santa Creu i Sant

Pau, Barcelona; ${ }^{20} \mathrm{H}$. Univ. Marqués Valdecilla, Santander; ${ }^{21} \mathrm{CH}$. Ourense,

Ourense; ${ }^{22} \mathrm{CH}$. Pontevedra, Pontevedra; ${ }^{23} \mathrm{H}$. Univ. Alicante, Alicante; ${ }^{24} \mathrm{H}$. Univ. Guadalajara, Guadalajara; ${ }^{25} \mathrm{H}$. General la Mancha Centro, Ciudad Real, Spain

Background: PsA has a higher heritability than PsV, indicating the existence of additional PsA-specific genetic factors. To date, however, the specific genetic basis underlying PSA is poorly understood.

Objectives: The objective the present study was to identify new genetic variation specifically associated with PsA risk.

Methods: In order to characterize the genetic basis of PsA, we performed a GWAS meta-analysis at the single-marker level as well as at the pathway level (GWPA). A cohort of 835 PsA patients and 1,558 controls from the Spanish population was genotyped for $>550,000$ SNPs. GWAS data from a second cohort of 1,430 PsA patients and 1,417 controls from the North American population 
was also used. In order to confirm the specificity of the new genetic variation associated with PsA risk, we analyzed the association with purely cutaneous psoriasis (PsC, $n=614$ ) and rheumatoid arthritis (RA, $n=1,191)$. We performed a pharmacogenetic analysis to investigate the new PsA-specific pathways as a source for drug discovery in PsA.

Results: GWAS meta-analysis identified a new association between B3GNT2 gene and PsA $(P<5 \mathrm{e}-08)$. In the GWAS pathway analysis, we identified and validated a total of 14 genetic pathways associated with PsA risk. From these, the glycosaminoglycan (GAG) metabolism pathway was also found to be significantly associated with PsA risk when directly contrasted to the PsC cohort as well as the RA cohort. At the functional level, we detected a significant differential expression of GAG metabolism pathway genes in blood samples from PsA patients compared to PsC patients. The pharmacogenetic analysis identified several FDA-approved drugs likely to modify the GAG pathway.

Conclusions: The present study represents an important step towards the characterization of the genetic factors specific to PsA risk.

Disclosure of Interest: None declared

DOI: 10.1136/annrheumdis-2017-eular.3685

\section{SAT0459 LOW DOSE IL-2 RESTORES IMBALANCE BETWEEN TH17 AND REGULATORY T CELLS IN PATIENTS WITH PSORIATIC ARTHRITIS}

K. Qin ${ }^{1}$, Q. Chen ${ }^{1}$, J. Fan ${ }^{1}$, D. Xu ${ }^{1}$, X. Li ${ }^{1}$, C. Wang ${ }^{1}$, C. Gao ${ }^{2} .{ }^{1}$ Rheumatology, the Second Hospital of Shanxi Medical University, Taiyuan, China; ${ }^{2}$ Pathology, Joint Program in Transfusion Medicine, Brigham and Women's Hospital/Children's Hospital Boston, Harvard Medical School, Boston, United States

Background: Psoriasis arthritis is one of chronic, relapsing, inflammatory autoimmune disorders with skin lesions and joint damage. A therapeutic revolution of psoriatic arthritis (PsA) is still a considerable unmet need in the past decades. It has been well known that the imbalance of Th17 cells and regulatory T cells (Tregs) may be a pivotal cause of PsA. Correction of this dysfunction can be a potential therapy of PsA.

Objectives: In this study, we measured and compared both absolute numbers and proportions of CD4+CD17+ Th17 cells and CD4+CD25+Foxp3+ Treg cells in peripheral blood of PsA patients and healthy controls to explore the immunopathogenesis of PsA; on the other hand, the effects of low-dose recombinant human IL-2 (rhIL-2) on Th17 and Treg cells were investigated in patients with PsA.

Methods: Both absolute numbers and proportions of Treg and Th17 cells in peripheral blood, defined as the CD4+CD25+Foxp3+T or CD4+IL-17+ T cell populations, were examined by flow cytometry in 40 healthy controls and 77 patients with PsA, including 39 patients who had never received diseasemodifying antirheumatic drugs (DMARDs) and 38 patients who were receiving or had received DMARDs. Among these patients, 20 patients consented at enrollment to receive $\mathrm{rhlL}-2$ treatment. Before and after treatment $(50 \mathrm{WIU} / \mathrm{d}$ for 5 days, $I H)$, Th17 and Treg cells in peripheral blood were analyzed by flow cytometry.

Results: The absolute count of Th17 cells in patients with PsA was very significantly higher than that of healthy controls $(P<0.01)$, but the proportions of Th17 cell were not seen difference between PsA and healthy controls $(P>0.05)$. In contrast with treated-PsA patients, the absolute count of Th17 cells was significant higher in untreated-PsA patients $(P<0.05)$. After the course of rhIL-2 treatment, there was a significant increase in the absolute count of Treg cells $(P<0.05)$, but no diference in the absolute count of Th17 cells, Th17/Treg was significantly lower and went back to nomal.

Conclusions: The results suggest that, not the proportion, but the decrease in the absolute count of Th17 cells, defined as the CD4+CD17+ populations, contributes to the pathogenesis of PsA. After the treatment of rhIL-2, there was a more significant increase in the absolute count of Treg cells than that of Th17, and consequently the balance of Th17/Treg was restored to normal, leading to the development of new therapies.

References:

[1] Karczewski J, Dobrowolska A, Rychlewskahańczewska A, et al. New insights into the role of $\mathrm{T}$ cells in pathogenesis of psoriasis and psoriatic arthritis[J]. Autoimmunity, 2016:1.DOI:10.3109/08916934.2016.1166214.

[2] Yoo I S, Lee J H, Song S T, et al. T-helper 17 cells: the driving force of psoriasis and psoriatic arthritis.[J]. International Journal of Rheumatic Diseases, 2012, 15(6):531-537. DOI:10.1111/j.1756-185X.2012.01813.x.

[3] Szodoray P, Nakken B, Barath S, et al. Altered Th17 cells and Th17/regulatory T-cell ratios indicate the subsequent conversion from undifferentiated connective tissue disease to definitive systemic autoimmune disorders[J]. Human Immunology, 2013, 74(12):1510-8. DOI:10.1016/..humimm.2013.08.003.

[4] Raychaudhuri S P. Role of IL-17 in psoriasis and psoriatic arthritis.[J]. Clinical Reviews in Allergy \& Immunology, 2013, 44(2):183-193. DOI: 10.1007/s12016-012-8307-1.

Disclosure of Interest: None declared

DOI: 10.1136/annrheumdis-2017-eular.6027

\section{SAT0460 ASSOCIATION BETWEEN INFLAMMASOME-RELATED POLYMORPHISMS AND PSORIATIC ARTHRITIS}

K. Juneblad ${ }^{1}$, A. Kastbom ${ }^{2}$, S. Rantapää-Dahlqvist ${ }^{1}$, P. Söderkvist ${ }^{3}$, G.-M. Alenius ${ }^{1} .{ }^{1}$ Dept of Public Health and Clinical Medicine/Rheumatology, University Hospital, Umeå, Umeå; ${ }^{2}$ Department of Clinical and Experimental Medicine, Rheumatology; ${ }^{3}$ Division of Cell Biology, Dept of Clinical and Experimental medicine, Linköping University, Linköping, Sweden

Background: In recent years, research on the interleukin 1 $\beta$ (IL1 $\beta)$-regulating protein complex, called the inflammasome, has shown interesting associations with various inflammatory diseases. E.g. for Rheumatoid Arthritis (RA) (1) and psoriasis (Pso) $(2,3)$ associations with genetic polymorphisms in genes related to the inflammasome has been discovered. So far, no studies investigating genetic polymorphisms in inflammasome genes in Psoriatic Arthritis (PsA) patients have been published.

Objectives: To examine whether polymorphisms in genes related to inflammasomes confer increased risk for psoriatic arthritis.

Methods: DNA from 771 PsA patients and 793 healthy controls from Sweden were analyzed for different single nucleotide polymorphisms (SNPs) in NLRP3 (rs35829419, rs 10733113, rs4353135), CARD8 (rs 2043211) and NLRP1 (rs8079034, rs878329).

Results: Significant associations with PsA were found between carriage of allele, $\mathrm{C}$, of rs878329 in NLRP1 (Chi-2=6.5, OR (95\% Cl); $0.75(0.60-0.94), \mathrm{P}=0.011)$ and allele $\mathrm{G}$ in rs4353135 in NLRP3 (Chi-2=4.8, OR (95\% Cl); 1.25 (1.02-1.53), $\mathrm{p}=0.028$ ). Genotype distribution were also significantly different between patients and controls and for rs878329 in NLRP1 there was a significant difference in allele frequency $(\mathrm{G} / \mathrm{C})$ between patients and controls (Chi-2 $=5.8$, OR $(95 \% \mathrm{Cl})$; 1.20 (1.03-1.38), $p=0.016$ ). No significant associations with PsA were found for the other SNPs analyzed.

In genotype analysis, a significant higher frequency of genotype GG in rs878329 in PsA was detected (32.9\% vs 26.9\%, Chi-2=6.49, OR (95\% Cl); 1.34 (1.07-1.67), $\mathrm{p}=0.011$ ), whilst no significant differences were detected for genotypes $G C$ or CC. For rs 4353135 , a significantly higher frequency of genotype TG $(43 \%$ vs $37.6 \%$, Chi-2=4.66, OR (95\% Cl); $1.25(1.02-1.53), \mathrm{P}=0.033)$ and a significantly lower frequency of genotype TT ( $50.5 \%$ vs $56.1 \%$, Chi- $2=4.85$, OR $(95 \% \mathrm{Cl}) ; 0.80$ $(0.65-0.98), P=0.028)$ was seen in PsA, no significan difference was detected for genotype GG.

Conclusions: Carriage of rs $878329 \mathrm{C}$ in NLRP1 was less frequent in patients with PsA compared with controls indicating a protecting effect, but when different genotypes were analysed the difference likely results from an increased risk of PsA with genotype GG. The results are in contrast with the study of Ekman et al, where an increased transmission of rs $878329 \mathrm{C}$ to family members with psoriasis was seen (3), indicating an increased risk of developing skin psoriasis for carriers of $\mathrm{C}$, but in agreement with the study of Sui et al on patients with $R A$, where an association was detected for carriage of $C$ (OR $0.82, p=0.02)$, with the risk genotype for RA being GG (4). Thus, the genotype GG possibly confers risk of arthritic disease whilst the $\mathrm{C}$-allele seems associated with skin disease. Carriage of rs $4353135 \mathrm{G}$ in NLRP3 was more frequent in PsA patients compared with controls indicating an increased risk of disease, but only genotype GT was significantly increased in PsA. The study is, to our knowledge, the first to study possible associations between genes related to the inflammasome and PsA. In the study associations were found between one SNP in NLRP3 and one SNP in $N L R P 1$, indicating a possible involvement in pathogenesis of PsA disease.

\section{References:}

[1] Rheumatol 2008:47:415-7.

[2] Exp Dermatol 2012;21:932-7.

[3] Br J Rheumatol 2014;171:1517-20.

[4] Arthritis Rheum 2012;64:647-54.

Disclosure of Interest: None declared

DOI: 10.1136/annrheumdis-2017-eular.3477

\section{SAT0461 CHARACTERISATION OF DIFFERENT LOW DISEASE ACTIVITY MEASUREMENTS IN PATIENTS WITH PSORIATIC ARTHRITIS}

L.C. Coates ${ }^{1}$, A.B. Gottlieb ${ }^{2}$, J.F. Merola ${ }^{3}$, L. Aikman ${ }^{4}$, A. Szumski ${ }^{5}$,

A. Chhabra ${ }^{6} .{ }^{1}$ University of Leeds, Leeds, United Kingdom; ${ }^{2}$ New York Medical College, New York; ${ }^{3}$ Harvard Medical School, Boston, United States; ${ }^{4}$ Pfizer, Walton Oaks, United Kingdom; ${ }^{5}$ InVentiv Health, Princeton; ${ }^{6}$ Pfizer, New York, United States

Background: Selection of the correct target to guide treatment is crucial for effective disease management in patients with psoriatic arthritis (PsA).

Objectives: To evaluate the prognostic value of several low disease activity (LDA) measurements in patients with PSA and psoriasis to assist physicians choose a valid target that facilitates assessment in clinical practice.

Methods: This was a post-hoc analysis from the PRESTA ${ }^{1}$ clinical study. LDA targets analyzed were: Disease Activity in PsA (DAPSA) LDA $\leq 14$ (tender joint count [TJC], swollen joint count [SJC], patient global visual analog scale [Pt VAS], pain VAS, C-reactive protein [CRP]; clinical (c)DAPSA LDA $\leq 13$ (DAPSA without CRP); and minimal disease activity (MDA) measurement defined as $5 / 7$ cut-offs (TJC $\leq 1$, SJC $\leq 1$, psoriasis activity and severity index [PASI] $\leq 1, \mathrm{Pt}$ pain $\leq 15 \mathrm{~mm}$, Pt VAS $\leq 20 \mathrm{~mm}$, health assessment questionnaire $\leq 0.5$, tender entheseal points $\leq 1$ ). Additional MDA measurements were investigated where $5 / 7$ 